\title{
2011 Scientific Achievement Award recipient: Marc R. de Leval, MD
}

\author{
Thomas L. Spray, MD
}

The American Association for Thoracic Surgery (AATS) presented the Scientific Achievement Award, one of the most prestigious honors that can be given by the AATS, to Dr Marc R. de Leval of London, England, during the 91st Annual Meeting in Philadelphia, Pennsylvania. Dr de Leval is an extraordinarily accomplished congenital cardiovascular surgeon, respected researcher, scholar, teacher and mentor, and an extraordinarily thoughtful individual.

Marc Roger de Leval was born in a small village in Belgium to a family of general practitioners. He undertook his medical school training at Liege University in Belgium and completed a residency in internal medicine and 3 years of general surgery training at the same institution. At that point, he decided to become a heart surgeon and, because there was no program for training in Liege, he applied for a fellowship at the Pacific Medical Center in San Francisco under Frank Gerbode. After 2 years in San Francisco, he was appointed as senior surgical registrar at the Great Ormond Street Hospital for Sick Children in London under David Waterston and Jaroslav Stark.

Professor de Leval was awarded the Evarts A. Graham Memorial Traveling Fellowship of the AATS and spent a year (1973-1974) at the Mayo Clinic under Robert Wallace, Dwight McGoon, and Gordon Danielson and then returned to Great Ormond Street Hospital where he was appointed to the staff in 1974. He continued his career at the Great Ormond Street Hospital for Sick Children until retirement from the National Health Service in 2006.

Dr de Leval has had an extraordinarily productive career of contributions to the field of cardiovascular surgery and to congenital cardiac surgery. As a fellow in California, he participated in the development of the use of the activated clotting time for heparin management for patients on cardiopulmonary bypass. This technique has now become standard in bypass management and was a major step forward in safe conduction of cardiopulmonary bypass and long-term support using extracorporeal membrane oxygenation.

Dr de Leval popularized the use of a prosthetic graft from the subclavian artery to the pulmonary artery (the modified Blalock-Taussig or Great Ormond Street shunt) as a way of permitting growth of the natural blood vessel to regulate

From the Division of Cardiology, Children's Hospital of Philadelphia, Philadelphia, $\mathrm{Pa}$.

Address for reprints: Ryan Walther, American Association for Thoracic Surgery, 500

Cummings Center, Suite 4550, Beverly, MA 01915 (E-mail: rwalther@aats.org). J Thorac Cardiovasc Surg 2012;143:767-8

$0022-5223 / \$ 36.00$

Copyright (c) 2012 by The American Association for Thoracic Surgery doi: 10.1016/j.jtcvs.2012.01.057 flow in a larger prosthetic graft to improve palliation of children with cyanotic congenital heart disease. The modified Blalock-Taussig shunt is now the standard approach to aortopulmonary shunting in a wide variety of heart lesions and has supplanted other shunts for its technical simplicity and reproducibility.

One of the major disadvantages of surgical repair in patients with Corrected Transposition of the Great Arteries with ventricular septal defect is the anomaly of the conduction tissue, which puts it at higher risk of damage during surgical repair. Dr de Leval, in association with Dr Robert Anderson, defined the conduction tissue distribution in corrected transposition and developed a technique for placing sutures to close the ventricular septal defect to avoid the very high incidence of complete heart block that had been previously seen with repair of this congenital heart condition.

Dr de Leval has been instrumental in developing a greater understanding of the Fontan circulation in single ventricle, and his extensive studies with the use of computational fluid dynamics and in vitro modeling of surgically reconstructed Fontan circulations led to the development of the total cavopulmonary connection (TCPC), which showed significant advantages over the previously standardized atriopulmonary Fontan connection, improving flow characteristics through the right side of the circulation and introducing the concept of laminar flow and reduction of power loss in the venous circulation that is critical for the long-term success of the Fontan circulation. Evolution of the TCPC principle lead others to the introduction of the extracardiac Fontan connection, and Dr de Leval's further studies of the extra-cardiac Fontan reinforced the importance of laminar flow and reduction in power loss in the circulation. The introduction of the concept of total cavopulmonary connection was a major advance in the field of single ventricle surgery.

Dr de Leval has continued his interest in mathematical modeling in surgical circulations. He has produced many contributions to the field of flow characteristics in single ventricle circuits by using computational fluid dynamics and finite element analysis. His analysis of the stages of reconstruction for hypoplastic left heart syndrome has led to an increased understanding of the circulatory characteristics in this complex congenital condition.

In addition to Professor de Leval's scientific contributions, he has also been one of the true pioneers in patient safety and risk management research. In the early 1980s, he became interested in the impact of human factors on surgical outcomes and undertook a series of studies looking at 
the human factors and errors in organizational accidents, which result in suboptimal outcomes in complex technology such as congenital cardiothoracic surgery. His earliest contributions looked at the role of human factors in pediatric cardiac surgery by using the arterial switch operation as a model. He was able to get all of the cardiac centers in the United Kingdom to participate in a study, which highlighted not only the importance of recovery from major errors and failures but also the importance of minor deficiencies that can have an additive impact, resulting in a poor outcome. In additional to this pioneering work on human factors, he also identified the very significant impact of communication among caregivers on the care of the patient after cardiothoracic surgery. He initiated an analysis of the role of human factors in handovers on outcomes at Great Ormond Street Hospital and, using comparison with other hightechnology, high-performance industries such as the aviation industry and the Formula One racing car industry, showed very clearly that human factors and communication lapses have multi-factorial effects on outcome and that implementing changes, including multi-disciplinary briefing and debriefing sessions before and after surgery and the use of checklists in the operating room have a significant impact on improving overall outcome. These areas of Dr de Leval's interests have now become extremely well recognized and many other researchers are continuing his pioneering work in this area.

Professor de Leval is known among his many admirers internationally as a surgeon of extraordinary intellect and an exceptionally introspective and critical thinker. His Honored Guest address at the 82nd Meeting of the American Association for Thoracic Surgery in Washington, DC, was an excellent summary of the issue of medical errors and the need to create systems to prevent the accumulation of minor errors and that can result in a poor surgical outcome.

Marc de Leval has been a true pioneer in the field of congenital cardiovascular surgery. He has contributed over 330 peer-reviewed publications to the literature on a wide range of topics in cardiac surgery and is the editor of one of the most popular and widely used textbooks of congenital cardiac surgery, now in its 3rd edition. He has been a mentor and teacher to a large number of the most prominent congenital cardiothoracic surgeons worldwide. He retired from active clinical practice in 2010. It was with a great deal of pride that the American Association for Thoracic Surgery awarded the Scientific Achievement Award of the AATS for 2011 to Marc Roger de Leval, MD, for a distinguished career of research contributions in multiple areas that have profoundly benefited the specialty of congenital cardiothoracic surgery. 